\title{
PHYSICAL PROPERTIES OF SILICON SENSOR STRUCTURES WITH PHOTOELECTRIC TRANSFORMATION ON THE BASIS

\begin{abstract}
A capability to produce effective sensor structures on the basis of "deep"silicon junction has been substantiated. If the incident light is strongly absorbed by this junction, the photocurrent through it is shown to substantially depend on the recombination characteristics and the charge state of the illuminated surface, provided that the junction parameters are optimal. The depth of the illuminated region is demonstrated to exceed the diffusion length of minority charge carriers. It is found that the larger diffusion length of minority charge carriers corresponds to stronger changes of the photocurrent generated by the illuminated surface area. A possibility to transform the junction from a photodetector into an effective chemical sensor is verified by numerical calculations. The physical mechanisms relating the changes in the effective surface recombination rate and the absorption of polar molecules are discussed. The sensor properties of suggested silicon junctions are analyzed for a number of analytes. Their suitability for the creation of selective chemical sensors (electronic noses) is demonstrated experimentally.
\end{abstract}

Ke ywords: solar cell, silicon junction, photocurrent, surface recombination rate.

\section{Introduction}

One of the main approaches to the creation of chemical sensors on the basis of semiconductor structures consists in that the influence produced by the adsorption of analyte molecules on the charge state of a working surface is used [1-3]. The physical mechanisms that govern the desired signal generated by a sensor depend on the type of semiconductor structure and the principle of implemented transformation $[4,5]$. It should be noted that the desired signal in the devices that are the most widespread nowadays is formed due to a variation of the conductivity (impedance).

(c) A.V. KOZINETZ, S.V. LITVINENKO, V.A. SKRYSHEVSKY, 2017
A lot of various devices are based on the electric mechanism of energy transformation. For example, in the structures on the basis of the metalsemiconductor contact [6], the matter of consideration is a modification of the metal work function owing to the analyte adsorption; in the structures on the basis of oxide semiconductors [7], this is a thickness variation of the space charge region; in the structures of the field-effect-transistor (FET) type, this is a variation of the threshold voltage in the inversion channel [8]; and so forth. The photo-electric principle of transformation is mainly used in light-addressable potentiometric sensors (LAPSs) [9]. The mechanism of desired signal formation in those devices is based on a variation of the thickness of the space charge layer in the electrolyte-insulator-semiconductor structure, which can be registered, when the specimen is illu-

ISSN 2071-0194. Ukr. J. Phys. 2017. Vol. 62, No. 4 
minated. For this purpose, additional measurements of alternating signals associated with the process of photo-induced barrier capacitance charging have to be carried out in a wide interval of the dc bias voltage (from the accumulation regime to the regime of surface region depletion in the semiconductor). Note that each of the mentioned structures has a definite scope of application, as well as specific properties and shortcomings. Therefore, the development of new types of sensor structures is a challenging task, in which new mechanisms governing the transformation of the analyte adsorption changes into the desired signal should be studied.

In our works $[10,11]$, the attention was paid to the fact that, under the analyte adsorption conditions, the recombination parameters of a working surface can change because of a variation of its charge state. Unlike the concepts that use the dependence of the conductance of a device on the adsorption, the surface recombination process can also be sensitive to this action. Since the physical mechanisms of this dependence differ from those that other transducers are based on, new devices will possess essentially distinct properties. A question arises: How can one register a variation of the surface recombination rate in such a way that the requirements of rapid measurement, device compactness, and others, which are imposed onto compact electronic sensors and their arrays, would be satisfied.

Under certain conditions, the photocurrent magnitude substantially depends on the surface recombination rate. When photosensitive semiconductor structures are illuminated, the concentration and distribution of light-generated charge carriers, as well as the photocurrent, depend on the light absorption and the bulk and surface recombinations. As a structure that "registers" the changes in the recombination processes running near the working surface, the $p-n$-junction can be applied. The usage of strongly absorbed light and the arrangement of a junction interface deeply enough from the illuminated surface enhance the influence of the surface recombination rate. Therefore, the photocurrent can reflect, in a certain sense, chemical and adsorption processes running at the interface with the analyte.

In this work, we substantiate a capability to use a deeply located silicon $p-n$-junction for the creation of chemical sensors, in which the photoelectric transformation mechanism is engaged. The model of

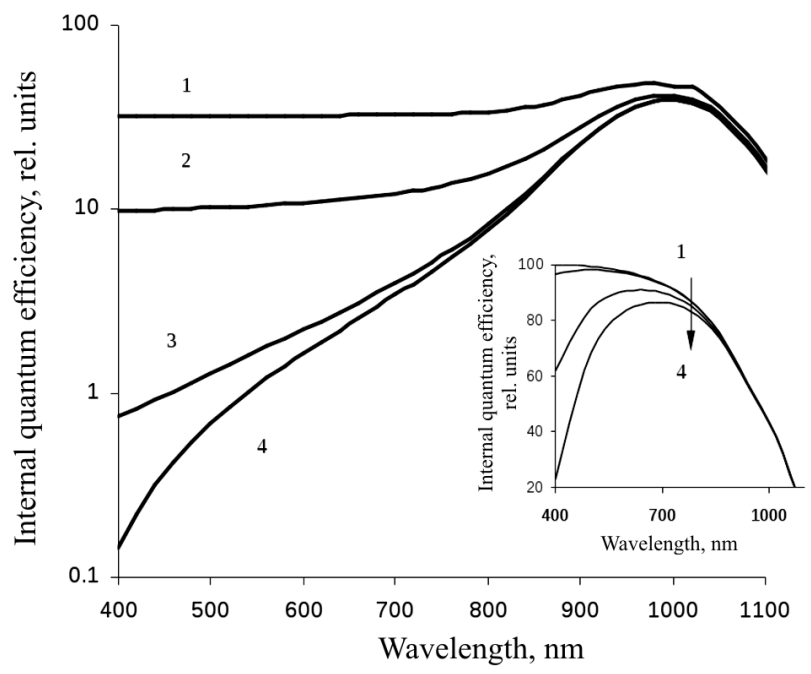

Fig. 1. Calculated dependences of the internal quantum efficiency on the wavelength for deep $(d=100 \mu \mathrm{m})$ and shallow ( $d=1 \mu \mathrm{m}$, the inset) junctions and $s=10^{2}(1), 5 \times 10^{3}$ (2), $10^{5}(3)$, and $10^{6} \mathrm{~cm} / \mathrm{s}(4)$. The hole diffusion length equals $90 \mu \mathrm{m}$ in all cases

such a sensor structure assumes that there is a relationship between the recombination characteristics of a working surface and the adsorption of analyte molecules. The aim of this work was to determine the junction parameters, which would allow the obtained variations of the desired signal (namely, the changes of the photocurrent through the junction) owing to the adsorption of polar molecules to be maximum, and to experimentally study the sensor properties of the structures concerned.

\section{Model of a Sensor Structure Based on the Silicon $\boldsymbol{p}-\boldsymbol{n}$-Junction}

Let us consider the features of the photocurrent formation in silicon junctions located at various depths $d$ in the case where they are illuminated with strongly absorbed light. For definiteness, we will consider the case where light illuminates the surface of the junction $n$-region. The recombination current toward the illuminated surface is assumed to be defined as the product of the surface recombination rate $s$ and the excess hole concentration. The calculated spectral dependences of the internal quantum efficiency of the $p-n$ junction for various values of parameter $s$ (the injection level is supposed to be low) are depicted in Fig. 1. The exhibited dependences were obtained with the use of the software PC-1D. The latter, by numer- 


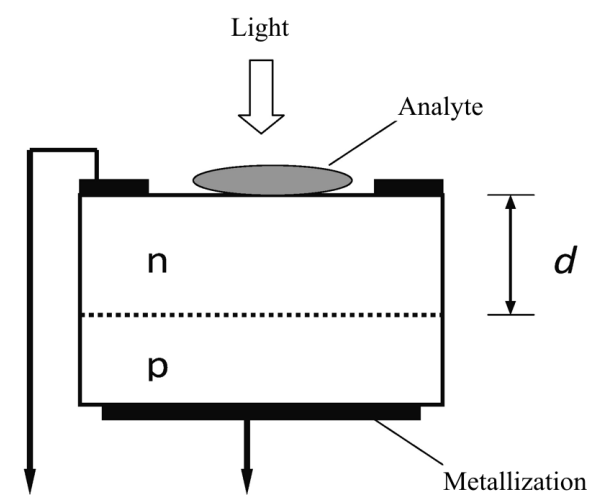

External circuit

Fig. 2. Schematic diagram of a sensor structure on the basis of a deep $p-n$ junction

ically solving the drift-diffusion equations, allows the photoelectric characteristics of various semiconductor structures to be analyzed. One can see that the variation magnitudes of spectral characteristics of the photocurrent in the short-wave spectral region that occur owing to a variation of the parameter $s$ are substantially different for the "deep" $(d=100 \mu \mathrm{m})$ and "shallow" ( $d=1 \mu \mathrm{m})$ junctions. Note that the hole diffusion length equals $90 \mu \mathrm{m}$ in both cases, and the other parameters of the structures are also identical.

As follows from the analysis of the curves shown in Fig. 1, the relative variations of the photocurrent are more substantial for the "deep" junction. This effect manifests itself in the wavelength interval, where silicon strongly absorbs light. Here, the absorption coefficient $\alpha(\lambda)=10^{5} \div 10^{3} \mathrm{~cm}^{-1}$, and the light penetration depth equals $0.1-10 \mu \mathrm{m}$. The parameters of the base $p$-region practically do not affect the formation of the junction photocurrent, because the main photo-induced generation takes place in the upper layer. For instance, the ratio $i\left(s_{1}=10^{2} \mathrm{~cm} / \mathrm{s}\right) / i\left(s_{2}=\right.$ $=10^{5} \mathrm{~cm} / \mathrm{s}$ ) equals about 10 for the wavelength $\lambda=500 \mathrm{~nm}$ and 16 for $\lambda=400 \mathrm{~nm}$. The obtained result can be explained by the fact that, in the case of "deep" junction, the region of light absorption and the region with a strong electric field are spatially separated from each other, and the majority of charge carriers are generated near the illuminated surface. The photocurrent collected by the $p-n$-junction is known to be proportional to the concentration gradient of nonequilibrium holes in the plane that corresponds to the boundary between the quasineutral and space charge regions, with the concentration of holes in this plane being close to zero owing to the action of the electric field generated by the space charge region. The stationary distribution of photo-generated holes is formed by two oppositely directed diffusion fluxes: toward the illuminated surface and toward the space charge region. It is the parameter of surface recombination rate that determines peculiarities in the concentration distribution of photo-generated holes in this situation. Therefore, the photocurrent magnitude also depends substantially on the surface recombination properties in the case of "deep" junction.

In Fig. 2, a schematic diagram of a sensor structure created on the basis of a deep $p-n$-junction is shown. As was mentioned in Introduction, the signal of this sensor is a photocurrent, which depends on the concentration of analyte molecules by means of the variation of surface recombination parameters. It was experimentally demonstrated that the variations of the surface recombination rate due to the adsorption of polar molecules on a germanium surface can reach 1 to 2 orders of magnitude $[12,13]$. Therefore, our further consideration will concern the indicated interval of surface recombination rate changes $s_{1}-s_{2}$ (the initial value of $s_{1}$ can be adopted to equal $10^{2}-10^{3} \mathrm{~cm} / \mathrm{s}$ ). The proposed sensor structure should provide the maximum variation of the photocurrent due to the variation of the surface recombination rate. Therefore, we should determine the optimum parameters of a $p-n$-junction (depth $d$, hole diffusion length, doping profile) and the optimal illumination conditions (wavelength). For the sake of convenience, it is expedient to estimate the relative variation of the photocurrent before and after the adsorption of analyte molecules, i.e. the ratio $i\left(s_{1}\right) / i\left(s_{2}\right)$.

Let us calculate the photocurrent ratio as a function of the junction depth: $i\left(s_{1}\right) / i\left(s_{2}\right)=f(d)$. In the case of uniform impurity distribution over the illuminated region, the photocurrent can be determined on the basis of exact solutions of the drift-diffusion equations. The expression for the photocurrent that arises in the junction $n$-region is written in the form

$$
\begin{aligned}
& i(s) \simeq \frac{e F \alpha l}{\alpha^{2} l^{2}-1} \times \\
& \times\left(\frac{\left(\frac{s l}{D}\right)+\alpha l-\exp (-\alpha d)\left[\left(\frac{s l}{D}\right) \operatorname{ch}\left(\frac{d}{l}\right)+\operatorname{sh}\left(\frac{d}{l}\right)\right]}{\left(\frac{s l}{D}\right) \operatorname{sh}\left(\frac{d}{l}\right)+\operatorname{ch}\left(\frac{d}{l}\right)}-\right. \\
& -\alpha l \exp (-\alpha d)),
\end{aligned}
$$


where $D$ is the hole diffusion coefficient, and $F$ the spectral flux density of light quanta. If the absorption is strong, i.e. at $\alpha(\lambda) l \gg 1$ and $\alpha(\lambda) d \gg 1$, the photocurrent magnitude is governed only by the absorption in the near-surface layer. Therefore, from formula (1), we obtain in this case that

$i(s) \simeq \frac{1+\frac{S}{\alpha(\lambda) D}}{s \frac{l}{D} \operatorname{sh}\left(\frac{d}{l}\right)+\operatorname{ch}\left(\frac{d}{l}\right)}$.

As a result, the photocurrent ratio is described by the expression

$\frac{i\left(s_{1}\right)}{i\left(s_{2}\right)}=\frac{1+\frac{s_{1}}{\alpha(\lambda) D}}{s_{1} \frac{l}{D} \operatorname{sh}\left(\frac{d}{l}\right)+\operatorname{ch}\left(\frac{d}{l}\right)} \frac{s_{2} \frac{l}{D} \operatorname{sh}\left(\frac{d}{l}\right)+\operatorname{ch}\left(\frac{d}{l}\right)}{1+\frac{s_{2}}{\alpha(\lambda) D}}$.

In Fig. 3, the dependences of the $i\left(s_{1}\right) / i\left(s_{2}\right)$ ratio on the junction depth are plotted for the case of surface recombination rates $s_{1}=10^{3} \mathrm{~cm} / \mathrm{s}$ and $s_{2}=10^{5} \mathrm{~cm} / \mathrm{s}$. The curve parameters are the wavelength $(\lambda=620,500$, and $400 \mathrm{~nm})$ and the hole diffusion length $(l=150,90$, and $50 \mu \mathrm{m})$.

From the results obtained, it follows that, from the viewpoint of sensor application, the optimal thickness of the $n$-region is determined by the diffusion length: at a fixed wavelength, a larger diffusion length corresponds to a larger photocurrent ratio. In the case where the $n$-region thickness exceeds the diffusion length, the dependences $i\left(s_{1}\right) / i\left(s_{2}\right)=f(d)$ saturate. At the same time, the increase of the absorption coefficient $\alpha(\lambda)$ at shorter wavelengths enhances the localization of photo-induced charge carriers near the illuminated surface, which results in the growth of the desired signal generated by the sensor structure.

Let us analyze the cases of uniform and nonuniform dopings in the illuminated region. For a nonuniform doping profile, the calculation of photocurrents is more complicated, because the coordinate dependences of the diffusion coefficient and the mobility of minority charge carriers have to be taken into consideration. Figure 4 illustrates the dependences of the $i\left(s_{1}\right) / i\left(s_{2}\right)$ ratio on the junction depth $d$, which were obtained with the help of a numerical simulation. Curves 1, 2, 3 and 5, 6, 7 in this figure correspond to a uniform doping profile (the diffusion length was determined with the help of the PC-1D code and amounted to 100,75 , and $40 \mu \mathrm{m}$, respectively), and curves 4 and 8 to a non-uniform one. In all variants, the increase of the junction depth gives rise to a gradual growth of the photocurrent ratio followed by the

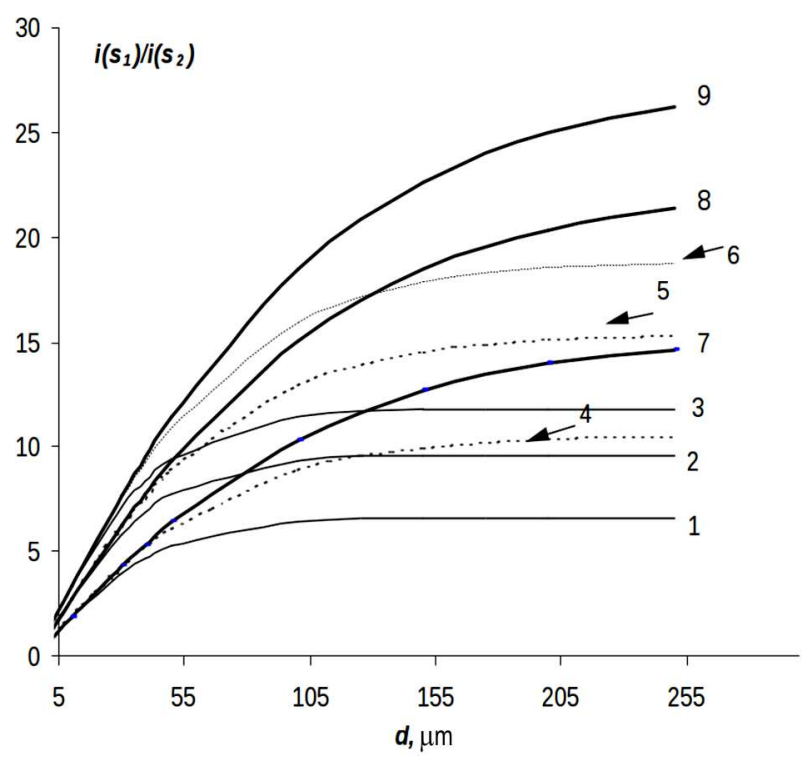

Fig. 3. Photocurrent ratio $i\left(s_{1}\right) / i\left(s_{2}\right)$ as a function of the junction depth $d$ for the wavelengths $\lambda=620(1,4,7), 520$ (2, $5,8)$, and $400 \mathrm{~nm}(3,6,9)$. The diffusion length equals 150 $(1,2,3), 90(4,5,6)$, and $50 \mu \mathrm{m}(7,8,9) ; s_{1}=10^{3} \mathrm{~cm} / \mathrm{s}$ and $s_{2}=10^{5} \mathrm{~cm} / \mathrm{s}$

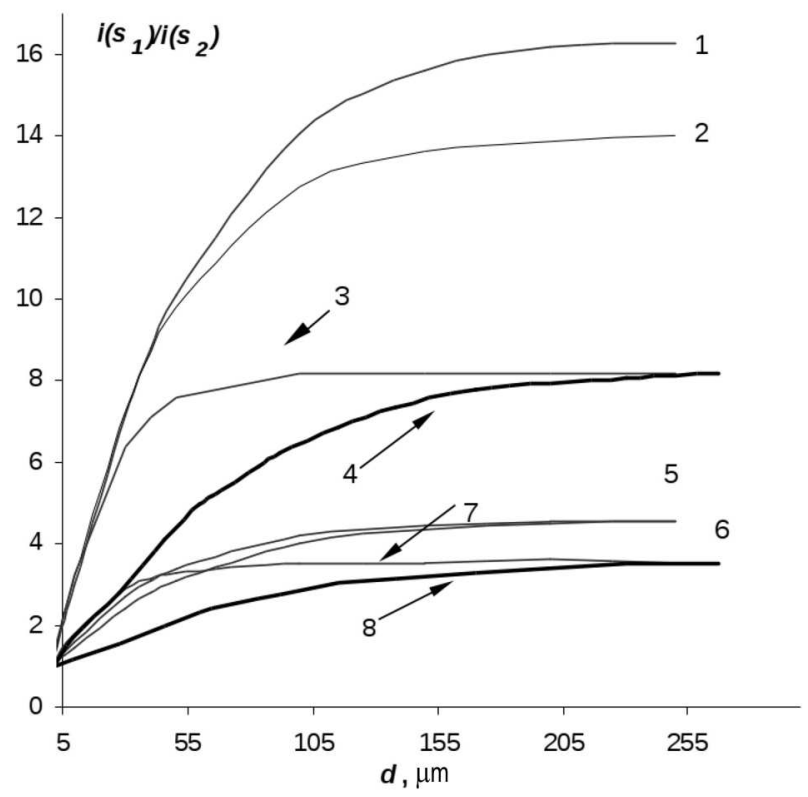

Fig. 4. Photocurrent ratio $i\left(s_{1}\right) / i\left(s_{2}\right)$ for the wavelength $\lambda=$ $=620 \mathrm{~nm}$ and for various doping levels of the $n$-region: $10^{16}$ $(1,5), 10^{17}(2,6)$, and $10^{18} \mathrm{~cm}^{-3}$; curves 4 and 8 correspond to the exponential profile with a maximum value of $10^{18} \mathrm{~cm}^{-1}$ near the illuminated surface. $s_{1}=10^{3} \mathrm{~cm} / \mathrm{s}, s_{2}=10^{4} \mathrm{~cm} / \mathrm{s}$ $(1,2,3,4) ; s_{1}=10^{2} \mathrm{~cm} / \mathrm{s}, s_{2}=10^{3} \mathrm{~cm} / \mathrm{s}(5,6,7,8)$ 
saturation. The maximum value of the $i\left(s_{1}\right) / i\left(s_{2}\right)$ ratio can be obtained in the case of the lowest uniform doping (curves 1 and 5), which corresponds to the largest hole diffusion length.

In the case of non-uniform exponential-like distribution profiles (curves 4 and 8 ), the value of ratio $i\left(s_{1}\right) / i\left(s_{2}\right)$ grows more slowly owing to the existence of a built-in electric field, which "pushes" the minority charge carriers away from the surface and reduces the influence of recombination processes. In particular, provided identical impurity concentrations, the values of $i\left(s_{1}\right) / i\left(s_{2}\right)$ ratio that are close to the values obtained in the case of uniform impurity distribution (curves 3 and 7) can be reached only if the thickness of the illuminated region is considerable (200$250 \mu \mathrm{m})$. The application of junctions with the indicated depth for sensor structures is not optimal, because the photocurrent magnitude substantially diminishes, and the photocurrent registration becomes a more complicated task.

Note that the junction depth for silicon phototransducers is selected to provide a more complete application of the short-wave interval in the sunlight spectrum and to optimize the series resistance of the emitter layer. Typical values of this parameter for solar cells are known to equal $0.3-0.5 \mu \mathrm{m}$. In this case, the non-uniform doping allows the influence of surface recombination to be reduced.

From the consideration above, it follows that, in order to obtain a maximum variation of the photocurrent owing to a change of the surface recombination rate in the sensor structure, a deep junction with a large diffusion length and a uniform profile of the doping impurity in the illuminated region of the wafer should be chosen. The optimum depth of a $p-n$-junction is close to the diffusion length. Those speculations testify in favor of a principal possibility to change the scope of silicon junction applications from a photo transducer to a sensor structure.

Let us consider the mechanisms that relate the adsorption processes with the variations of the surface recombination rate on the working surface of a silicon sensor structure. The adsorption of polar molecules is known to result in the appearance and fixation of specific electric dipoles on the surface $[12,13]$. Accordingly, the local action of an electric field in the near-surface region can induce changes in the energy position of recombination levels, their con- centration, capture cross-sections, and near-surface band bending. The capture or injection of electrons from the semiconductor bulk in the case of chemisorption can be an additional factor contributing to the band bending.

Model ideas about the relationship between the surface recombination and the band bending were developed in the Stevenson-Keyes theory and its complicated variants. The latter consider the cases of multivalent recombination centers, centers with a continuous energy distribution in the forbidden gap, a high injection level, and others [15-17]. In the framework of such theories, the effective surface recombination rate is usually considered as equal to that in a plane corresponding to the interface between the surface space charge region and the quasineutral region. The dependence of the surface recombination rate on the band bending, $s(Y s)$, has a pronounced maximum in the case where the near-surface concentration values are close to one another. It also has intervals of a drastic recession for band bendings corresponding to the accumulation or depletion regimes [18]. The main criterion for the concept of effective surface recombination rate to be applied correctly is the approximation of equilibrium between the surface and the quasineutral bulk of a semiconductor or the so-called approximation of "gradientless Fermi quasilevels" (in practice, this means that the diffusion length should considerably exceed the dimensions of the near-surface space charge region). This condition is satisfied for silicon in a wide range of parameters $[15,16]$.

To summarize, the following main cases can be distinguished.

(i) Due to the adsorption, the initial band bending changes, which invokes a transition into the accumulation or depletion regime. The effective recombination decreases at that owing to the deficiency of charge carriers with the corresponding sign. Conversely, the change of the initial band bending stimulates a transition from the accumulation or depletion regime to the regime with close nearsurface concentrations of charge carriers. The effective recombination increases at that.

(ii) Due to the adsorption, the concentration of recombination centers changes, which affects the recombination rate at the maximum of the $s(Y s)$ curve.

(iii) Due to the adsorption, the capture crosssections of recombination centers change, and the cor- 
responding shift of the maximum takes place with respect to the previous $Y s$ values.

Evidently, either a combined or selective realization of those effects is possible for the surface of a real sensor structure.

\section{Sensitivity of Sensor Structures on the Basis of "Deep" Silicon $p-n$-Junction. Results of Experimental Research}

Figure 5 demonstrates the surface (2D) distributions of the photocurrent generated by deep $p-n$-junctions that are in contact with a number of polar media. The value of $2 \mathrm{D}$-distribution function at every surface point was calculated as the ratio between the photocurrent magnitudes obtained, when the structure contacts with a definite medium and with air (free surface). This approach makes it possible to compare the changes of a sensor signal with regard for the inhomogeneous distribution of band bendings near the surface. The illuminated surface was not metallized. Some part of its area was covered with thin (up to $100 \mathrm{~nm}$ ) $\mathrm{SiN}_{x}$ film stripes in order to study the selectivity of the sensor response under conditions of the artificially created inhomogeneity (see the inset in Fig. 5) $[19,20]$. As a result, the analyte was in contact with both the silicon surface and $\mathrm{SiN}_{x}$ stripes. The structure surface was illuminated with light with the wavelength $\lambda=532 \mathrm{~nm}$. For this purpose, a semiconductor laser equipped with a system of acoustoelectric positioning was applied [21].

In our case, we used single-crystalline silicon wafers intended for the manufacture of industrial solar cells. Unlike the solar cell, the sensor structure has to be illuminated from the base side (the doping of the base region was moderate, which gave a specific resistance of about $1 \Omega \cdot \mathrm{cm}$ ). The junction depth was $250 \mu \mathrm{m}$, the diffusion length of minority charge carriers was equal to about $200 \mu \mathrm{m}$, and the doping profile was uniform. According to the theoretical consideration, the photocurrent substantially depends on the effective recombination rate in the researched structures. On the other hand, the changes of the surface recombination parameters (band bending, spectrum of electron states, capture cross-sections, and others) affect the photocurrent inasmuch as they govern the variations of the surface recombination rate. The non-uniform character of the distribution functions in Fig. 5 is evidently associated with the inhomogeneous distribution of defects over the wafer surface.

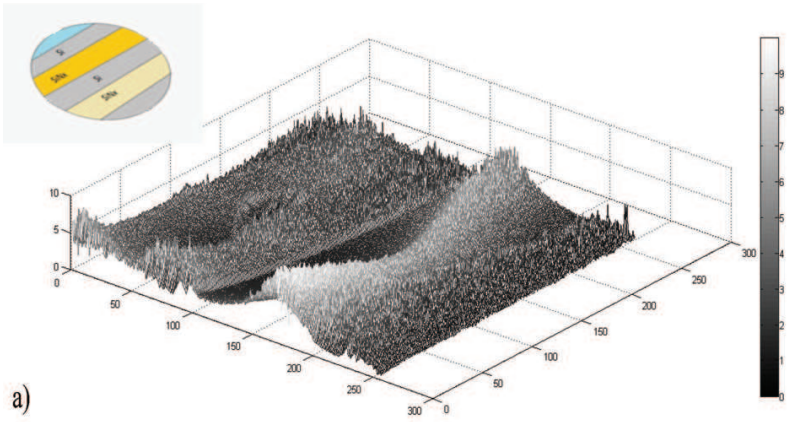

b)
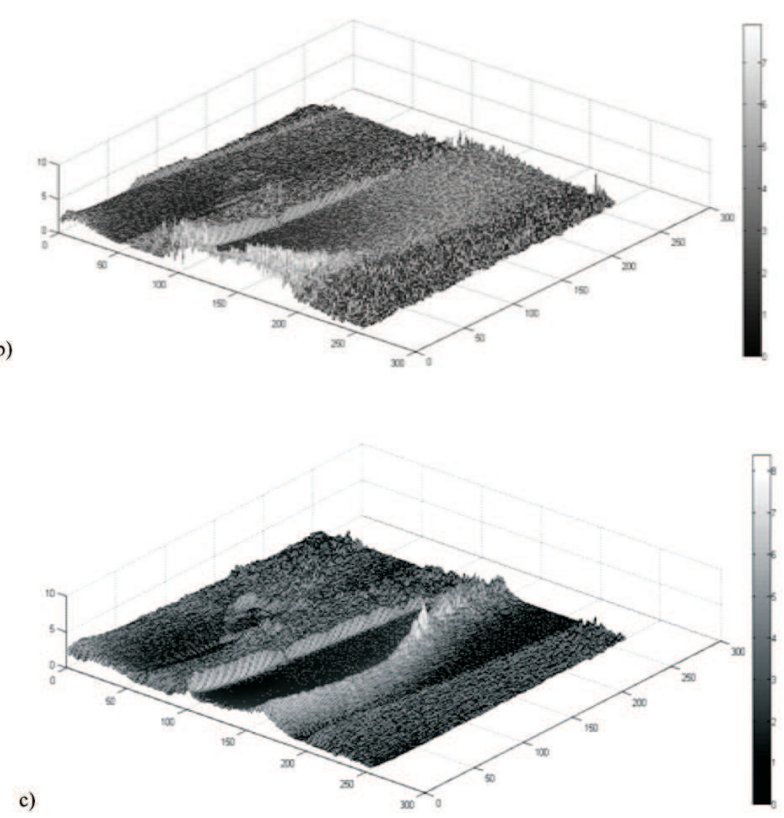

Fig. 5. 2D distribution functions for the photocurrent of deep $p-n$ junctions, when the surface is in contact with various polar media: ethanol $(a)$, isopropyl alcohol $(b)$, and water $(c)$. The image of the surface of a deep $p-n$ junction covered with stripes of thin $\operatorname{SiN}_{x}$ films are shown in the inset

The analysis of experimental data testifies that, for each of three polar media, the photocurrent changes differently in comparison with the case of free-surface illumination. Such variations of the photocurrent can evidently be explained only by changes of the recombination characteristics of the illuminated surface due to the adsorption (obviously, the bulk junction parameters are not changed). We may assume that the contact with each of three examined media results in different near-surface band bendings $Y s$ in comparison with that for the surface free from the analyte. Therefore, the relationship between the photocurrent changes and the analyte adsorption on the 
working surface has to be considered on the basis of variations in the effective surface recombination rate $s$.

Note that a certain growth of the sensor signal is observed for the surface areas covered with the $\mathrm{SiN}_{x}$ film. A detailed analysis of this effect can be a matter of further researches. Now, we can only assume that if the concentration of surface states at the silicon surface is high, a specific "fixation" of the Fermi level near the surface takes place, so that the adsorption does not result in substantial modifications of the initial band bending. The $\operatorname{SiN}_{x}$ film partially passivates those surface states at the silicon surface, which provides the growth of the sensitivity. The influence of the microrelief of the $\mathrm{SiN}_{x}$ film surface can be another probable origin of this effect.

As follows from the experimental results, the character of the surface distribution of the sensor signal is different for each of the researched media. As was already mentioned above, those photocurrent distributions were calculated by dividing the distribution data obtained in the presence of a definite medium by the corresponding data obtained in the air atmosphere. The fact that the presented distributions are different testifies to the selectivity of sensor structures and allows us to assume those structures to be suitable for the creation of complicated sensor systems of the type of electronic nose or electronic tongue [19]. Note that the examined structures demonstrate a good reproducibility of results in a cycle of five measurements with the use of test media.

As was already mentioned, the photoelectric mechanism of energy transformation is used in lightaddressable potentiometric sensors. However, its application in the proposed structures has some specific features and advantages. First, the structure concerned allows the sensor signal to be measured even if no external voltage is applied (or at such voltages when a near-surface accumulation region appears and directly in gas media). Second, there is no necessity of using the rear illumination for both main and reference electrodes. Information obtained with the help of the proposed sensor structure is based on basically different physical mechanisms in comparison with the known sensor structures (FETs, LAPSs). This circumstance enhances the capability to distinguish media, when the sensor is used in an electronic nose system. Furthermore, in due course, the proposed sensor structure may also find its spe- cific domains of application. Note that the adsorption efficiency of the proposed sensor structure can be improved by covering the junction surface with thin layers possessing a developed surface (for instance, layers of porous silicon or other nanocrystalline substances).

\section{Conclusions}

A capability to use deep silicon $p-n$-junctions for the creation of effective sensor structures has been analyzed. On the basis of numerical calculations, it is demonstrated that if a deep silicon junction is illuminated with light belonging to the spectral interval of strong absorption, its photocurrent substantially depends on the recombination characteristics and the charge state of the surface, provided that the junction parameters are optimal. Larger diffusion lengths in the illuminated region are found to correspond to larger photocurrent changes at the adsorption on the working surface. The optimum junction depth in the sensor structure should be close to the diffusion length or exceed it. It is also expedient to choose a uniform doping profile. Physical mechanisms that can relate variations in the effective recombination rate with the adsorption processes of polar molecules are proposed. The photocurrent changes in the examined sensor structures are shown to be driven by a modification of recombination characteristics of the structure surface arising owing to the contact of the surface with various analytes. The suitability of the considered sensor structure for the creation of chemical sensors with the selectivity function is demonstrated.

1. P. Bergveld. The impact of MOSFET-based sensors. Sensor. Actuat. 8, 109 (1985) [DOI: 10.1016/02506874(85)87009-8].

2. S.M. Sze. Semiconductor Sensors (Wiley, 1996) [ISBN: 978-0471546092].

3. L. Ristic. Sensor Technology and Devices (Artech House, 1994) [ISBN: 0-89006-532-2].

4. V.G. Litovchenko, T.I. Gorbanyuk, V.S. Solntsev, A.A. Evtukh. Mechanism of hydrogen, oxygen and humidity sensing by $\mathrm{Cu} / \mathrm{Pd}$-porous silicon-silicon structures. Appl. Surf. Sci. 234, 262 (2004) [DOI: 10.1016/j.apsusc.2004.05.146].

5. V.G. Litovchenko, T.I. Gorbanyuk, A.A. Efremov, A.A. Evtukh, D. Schipanski. Investigation of MIS gas sensitive structures with $\mathrm{Pd}$ and $\mathrm{Pd} / \mathrm{Cu}$ metal layers. Sensor. Actuat. A 74, 233 (1999) [DOI: 10.1016/S09244247(98)00314-8].

ISSN 2071-0194. Ukr. J. Phys. 2017. Vol. 62, No. 4 
6. G.J. Li, X.H. Zhang, S. Kawi. Relationships between sensitivity, catalytic activity, and surface areas of $\mathrm{SnO}_{2}$ gas sensors. Sensor. Actuat. B 60, 64 (1999) [DOI: 10.1016/S0925-4005(99)00245-2].

7. S. Pitcher, J.A. Thiele, H. Ren, J.F. Vetelino. Current/voltage characteristics of a semiconductor metal oxide gas sensor. Sensor. Actuat. B 93, 454 (2003) [DOI: 10.1016/S0925-4005(03)00166-7].

8. P. Feng, F. Shao, Y. Shi. Q. Wan. Gas sensors based on semiconducting nanowire field-effect transistors. Sensors 14, 17406 (2014) [DOI: 10.3390/s140917406].

9. T. Wagner, M.J. Schoning. Light-addressable potentiometric sensors (LAPS): Recent trends and applications. Electrochem. Sensor Anal. 49, 87 (2007) [DOI: 10.1016/S0166526X(06)49005-X].

10. S.V. Litvinenko, A.V. Kozinetz, V.A. Skryshevsky. Concept of photovoltaic transducer on a base of modified $p-n$ junction solar cell. Sensor. Actuat. A 224, 30 (2015) [DOI: 10.1016/j.sna.2015.01.014].

11. O.V. Kozynets, S.V. Litvinenko. Physical properties of sensor structures on the basis of silicon $p-n$ junction with interdigitated back contacts. Ukr. J. Phys. 57, 1234 (2012).

12. Yu.V. Novotnitskii, M.I. Sinyukov. The influence of polar molecules absorption on surface properties of germanium. In Surface Properties of Semiconductors (Izd. Akad. Nauk SSSR, 1962), p. 62 (in Russian).

13. I.G. Neizvestnyi. About influence of absorption of ether moleculs in germanium on the parameters of recombinational centers. In Surface Properties of Semiconductors (Izd. Akad. Nauk SSSR, 1962), p. 78 (in Russian).

14. S.M. Sze, Physics of Semiconductor Devices (Wiley, 1981).

15. A.P. Gorban, V.P. Kostylyov, A.V. Sachenko, A.A. Serba, I.O. Sokolovsky. Impact of excess charge carrier concentration on effective surface recombination velocity in silicon photovoltaic structures. Ukr. J. Phys. 51, 598 (2006).

16. A.V. Sachenko, O.V. Snitko, Photo-Effects in NearSurface Layers of Semiconductors (Naukova Dumka, 1984) (in Russian).

17. A.V. Rzhanov. Electronic Processes at Semiconductor Surface (Nauka, 1971) (in Russian).

18. G.P. Peka. Physical Phenomena at Semiconductor Surfaces (Vyshcha Shkola, 1984) (in Russian).

19. S.V. Litvinenko, D. Bielobrov, V. Lysenko, T. Nychyporuk, V.A. Skryshevsky. Might silicon surface be used for elec- tronic tongue application? ACS Appl. Mater. Interfaces 6, 18440 (2014) [DOI: 10.1021/am5058162].

20. S.V. Litvinenko, D. Bielobrov, V. Lysenko, V.A. Skryshevsky. Optical addressing electronic tongue based on low selective photovoltaic transducer with nanoporous silicon layer. Nanoscale Res. Lett. 11, 374 (2016) [DOI: 10.1186/s11671-016-1589-0].

21. S. Litvinenko, L. Ilchenko, A. Kaminski, S. Kolenov, A. Laugier, E. Smirnov, V. Strikha, V. Skryshevsky. Investigation of the solar cell emitter quality by LBIC-like image techniques. Mat. Sci. Eng. B 71, 238 (2000) [DOI: 10.1016/S0921-5107(99)00382-7].

Received 27.11.16.

Translated from Ukrainian by O.I. Voitenko

О.В. Козинецъ, С.В. Литвиненко, В.А. Скришевсъкий

\section{ФІЗИЧНІ ВЛАСТИВОСТІ КРЕМНІЕВИХ} СЕНСОРНИХ СТРУКТУР $З$ ФОТОЕЛЕКТРИЧНИМ ПРИНЦИПОМ ПЕРЕТВОРЕННЯ НА ОСНОВІ "ГЛИБОКОГО" $p-n$-ПЕРЕХОДУ

$\mathrm{P}$ е $з$ ю м е

В роботі обгрунтовано можливість використання кремнієвого переходу для ефективних сенсорних структур. Показано, що в умовах опромінення світлом з області сильного поглинання фотострум суттєво залежить від рекомбінаційних характеристик та зарядового стану поверхні у випадку оптимальних параметрів переходу. Визначено, що товщина освітлюваної області для такої структури повинна перевищувати довжину дифузії неосновних носіїв заряду. Визначено також, що більшій довжині дифузіі відповідають більші зміни фотоструму при адсорбції на робочій поверхні. 3 використанням числового моделювання проаналізовано можливість зміни області застосування переходу від фотоперетворювача до сенсорної структури при певному виборі його параметрів. Обговорено фізичні механізми, які можуть пов'язувати зміни ефективної швидкості із процесами адсорбції полярних молекул. Сенсорні властивості запропонованих структур досліджено для декількох аналітів. Експериментально продемонстровано придатність такої структури для створення хімічних сенсорів, які мають функцію селективності та підтримують концепцію електронного носу. 